\title{
SÍNTESE E COMPLEXIDADE NO PENSAMENTO GEOGRÁFICO
}

\author{
Synthesis and Complexity in Geographic Thinking
}

Cinthia Maria de Sena Abrahão

Doutoranda em Geografia pela Universidade Federal do Paraná

Matinhos /PR - Brasil

cisena@terra.com.br

Artigo recebido para publicação em 02/11/08 e aceito para publicação em 14/07/09

RESUMO: Neste artigo tratamos dos marcos da Geografia Moderna através da reflexão sobre os elementos que caracterizaram a influência do romantismo alemão. Para tanto, destacamos a herança humboltiana e de alguns de seus seguidores, que estiveram em expedições pela América ao longo do século XIX. Através da obra destes cientistas é possivel perceber o esforço de interconectar formas de compreensão da realidade que foram consideradas incompativeis pela ciência moderna, a racional e a artística. Contemporaneamente percebe-se um percurso da Geografia em busca de uma nova matriz científica, que dê suporte à complexidade dos fenômenos. Neste contexto, confirma-se e revitaliza-se a necessidade de refletir sobre as contribuições dos naturalistas viajantes do século XIX.

Palavras-chave: Geografia. Complexidade. Viajantes-naturalistas.

ABSTRACT: In this article we treat some elements of the Modern Geograhy, a view of the reflections above the heritage of Humbolt and about his followers, who were in expeditions by America along the 19th century. Across the work of these scientists it is possible perceive the effort of interconnecting fields of the knowledge that were dichotomized by the modern science, the reason and artistic languages. Nowadays, it's perceptible a way of the Geography in pursuit of a new scientific base to comprehend the phenomenon complexity. In this context, it is confirmed and revitalized the requirement of reflections about the naturalists from $19^{\text {th }}$ century.

Keywords: Geography. Complexity. Naturalist-travellers.

\section{INTRODUÇÃO}

O processo histórico, que deu configuração à modernidade capitalista, trouxe em sua esteira, a trajetória de um modo de vida que se tornou hegemônico e, sobretudo, combinou de forma complexa as maneiras de refletir o mundo e a materialidade da existência humana. A consolidação do capitalismo, ao contrário do que supõe a leitura positiva da história, se configurou de forma não linear. Trouxe em seu contexto a dinâmica das contradições e incongruências presentes mesmo depois da sua instituição como modo de produção hegemônico.

A mudança da percepção e da ação humana em relação ao seu entorno, permitindo que este repre- 
sentasse a natureza como algo que lhe é externo, foi consolidada nos processos que se conformarão e darão título ao que chamamos de modernidade. A transição lenta e gradual da era medieval, na Europa Ocidental, para a etapa de hegemonia do capitalismo trouxe os elementos constitutivos e reflexivos deste processo. A natureza, a partir da interferência humana, assumiu a condição de meio, extensão e movimento, coisa passível de dominação e reprodução. Algo compreensível através do estabelecimento de leis, paradigmas científicos, que permitiriam desvendar todos e quaisquer mistérios de sua existência. A atitude contemplativa dava lugar à ação de domínio e controle.

A primeira etapa da transição para o capitalismo fez emergir um conjunto de questionamentos no campo das idéias que consolidou o resgate dos fundamentos filosóficos da Idade Antiga. Esta etapa foi nomeada como Renascimento na história das ciências. As raízes do pensamento geográfico moderno também estão vinculadas a este ponto de partida. Na Antiguidade Clássica, a partir da teorização de Eratóstenes e Ptolomeu, a geografia tinha o objetivo de determinar coordenadas de lugares na superfície da Terra (CLAVAL, 2002). Percebe-se enraizada na Geografia a ordem fundante desta lógica de relacionamento do homem com o externo, na busca de perceber o espaço, que se transformou paulatinamente em busca pela dominação da natureza.

A expansão comercial no continente europeu representou um dos elos de ruptura da estrutura feudal predominante. Contudo, pode-se pensar no elevado impacto que as navegações e a expansão ultramarina provocaram sobre o modo de pensar e agir dos europeus, a partir do século XVI. A descoberta do novo continente, em especial das regiões tropicais, representou questionamentos efetivos às verdades estabelecidas até então. $\mathrm{O}$ fortalecimento da burguesia e de seus desígnios representou por si, um processo descontinuado, complexo e desigual mesmo se pensado dentro do continente europeu. Contudo, foi suficientemente forte para abalar a estrutura de pensamento moldada sob a lógica da escolástica medieval. Contribuindo assim para que novas formas de interpretação passassem a ser possíveis e até mesmo, crescentemente necessárias.
Partindo deste ambiente de discussão, o presente texto tem por objetivo versar sobre o surgimento da Geografia, inserida no quadro das ciências modernas. $\mathrm{O}$ foco está na compreensão da natureza como seu objeto de interpretação a partir da análise histórica, tendo por base as transformações sócio-econômicas e culturais. Além disso, pretende destacar características fundantes do pensamento geográfico, especialmente a partir da influência do romantismo alemão e em especial de Alexander Von Humboldt, naturalista, considerado um dos fundadores da Geografia Moderna.

Considerando os objetivos desenhados, o texto foi organizado em três partes. Na primeira, destaca o ressurgimento da natureza como objeto da reflexão humana, partindo da história da filosofia. Nesta etapa do artigo procuramos estabelecer um diálogo com a expressão artística, em especial com a pintura, com vistas a expressar de que forma a natureza passou a ser percebida. Perfazemos um breve caminho do renascimento até as contribuições do romantismo alemão através da obra de Humboldt, onde se evidencia uma busca de fusão dos dois caminhos perceptivos da realidade, o científico e o artístico. Na segunda parte, tratamos o surgimento da Geografia moderna ainda sob a ótica do romantismo alemão, tendo por base a realidade do "novo" mundo. Aqui, o texto procura elucidar a proposição romântica de compreensão da complexidade do objeto geográfico, que suplanta originariamente a dualidade entre o físico e o humano.

Entendemos que a busca de referência nesta corrente de pensamento, o romantismo, enquanto sistemática de compreensão, seja capaz de revelar um caminho perdido da modernidade. Interessa-nos resgatá-lo, sobretudo por considerarmos as questões pautadas contemporaneamente, em tempos de crise de paradigmas do pensamento moderno. Neste sentido, fazemos alusão ao trabalho de alguns dos naturalistas viajantes que estiveram pela América. Por fim, concluímos discutindo a recolocação da síntese científica no debate contemporâneo da ciência geográfica, procurando destacar as contribuições possíveis do resgate das experiências analisadas ao longo do artigo. 


\section{DA FILOSOFIA RENASCENTISTA AO RO- MANTISMO DE HUMBOLDT}

A confiança na razão foi resgatada da civilização greco-romana, passando a se constituir enquanto fundamento social na Idade Moderna. $\mathrm{O}$ argumento racional passou a se correlacionar de forma cada vez mais contundente à pretensão humana de abarcar $o$ mundo. O ponto de partida esteve centrado na idéia de que não existe um mundo uno e ordenado, que se propõe ao reconhecimento humano, contrariamente àquele percebido pelo pensamento greco-romano. Explicitava-se um "novo" mundo, diverso, relativo e complexo, que iria requerer fundamentos eficazes para sua compreensão efetiva. Em nome desta necessidade de compreensão foi resgatada a idéia de razão.

A expressão máxima deste modelo está na matemática, em sua raiz etimológica, ta mathema, conhecimento completo, tido como inteiramente racional. Os métodos inerentes aos estudos matemáticos tornaramse referência fundamental, não apenas no sentido da quantificação, mas do estabelecimento de teoremas. Instaurou-se aí uma obsessão moderna da filosofia em busca dos métodos, dos elementos mediadores entre o problema e a verdade racional (ABRÃO, 1999).

O momento de ruptura que estas novas idéias proporcionaram remete-nos, ainda no século XVI, a Francis Bacon, cuja tese empirista foi aprofundada por Galileu. A partir da obra de Bacon, observação, descrição e isenção das idéias preconcebidas tornaram-se condições necessárias para a análise dos fenômenos. Além disso, propunha a metodologia da experimentação, capaz de permitir a descrição rigorosa e precisa, a variação das condições ambientais, bem como as comparações (BACON, 1999).

A ciência nascente a partir do racionalismo e do experimentalismo de Bacon empoderava o humano neste processo de compreensão do mundo natural e, atrelado a isto, o domínio de outros povos e culturas por parte dos europeus ocidentais. Dominação que passa a ser realizada a partir do manto da razão humana.

Considere-se ainda, se quiser, quanta dife- rença há entre a vida humana de uma região das mais civilizadas da Europa e uma região das mais selvagens e bárbaras da Nova Índia [referência à América]. Ela parecerá tão grande que se poderá dizer que o "O homem é Deus para o homem”, não só graças ao auxílio e beneficio que ele pode prestar a outro homem, como também pela comparação das situações. E isto ocorre não devido ao solo, ao clima ou à constituição física. (BACON, 1999, p. 97).

Bacon afirmava em sua análise, não só a relevância do surgimento do fenômeno representado pelo "novo mundo", mas, sobretudo a relação entre o conhecimento científico e o poder de dominação, que se estende ao campo natural, bem como para o humano. Nas palavras de Bacon, "saber é poder".

Nesta mesma etapa da história é possível também estendermos nosso olhar para outro campo da percepção humana, e observar o aflorar do renascimento na forma como foi lido pela Arte. Paulatinamente, os temas pagãos foram emergindo na pintura, rompendo com a leitura escolástica da pintura medieval. E, na medida em que as novas temáticas adentraram o universo da pintura, a natureza também passou a ser expressa de forma completamente distinta, como elemento vivo e dinâmico, ao tempo em que a centralidade humana torna-se presente.

Tendo em vista elucidar este raciocínio, podemos analisar duas obras muito significativas no debate sobre o renascimento na Arte. A primeira delas é do pintor Veneziano Giorgine, de 1505, cujo título é $A$ Tempestade (FIG. 1). Giorgine era discípulo de Belini, precursor do renascimento na arte em Veneza. Na obra de Belini a natureza objetivava ser vista aos olhos de São Francisco, como parte da criação divina. Sob outra proposição, Giorgine parece promover uma ruptura importante em relação a esta visão na tela citada, onde a natureza e a sensualidade humana (que se tornariam elementos de uma nova tradição na pintura) não estão submetidas da mesma forma. $\mathrm{O}$ fenômeno natural aparece como elemento vivo e dotado de importância particular na tela (JANSON, 1988, p.218). 
Esta mesma intencionalidade de Giorgine está expressa na tela de Ticiano, o Bacanal (FIG. 2), mas as figuras humanas assumem um protagonismo explícito. Embora expresse a influência da arte clássica, ao mesmo tempo rompe com a mesma, no processo interativo entre seres de carne e osso, inspirados nos deuses gregos. Nesta obra de 1518, Ticiano traz os deuses gregos para a condição de humanos, remetendonos a uma nova relação entre o homem e a natureza.

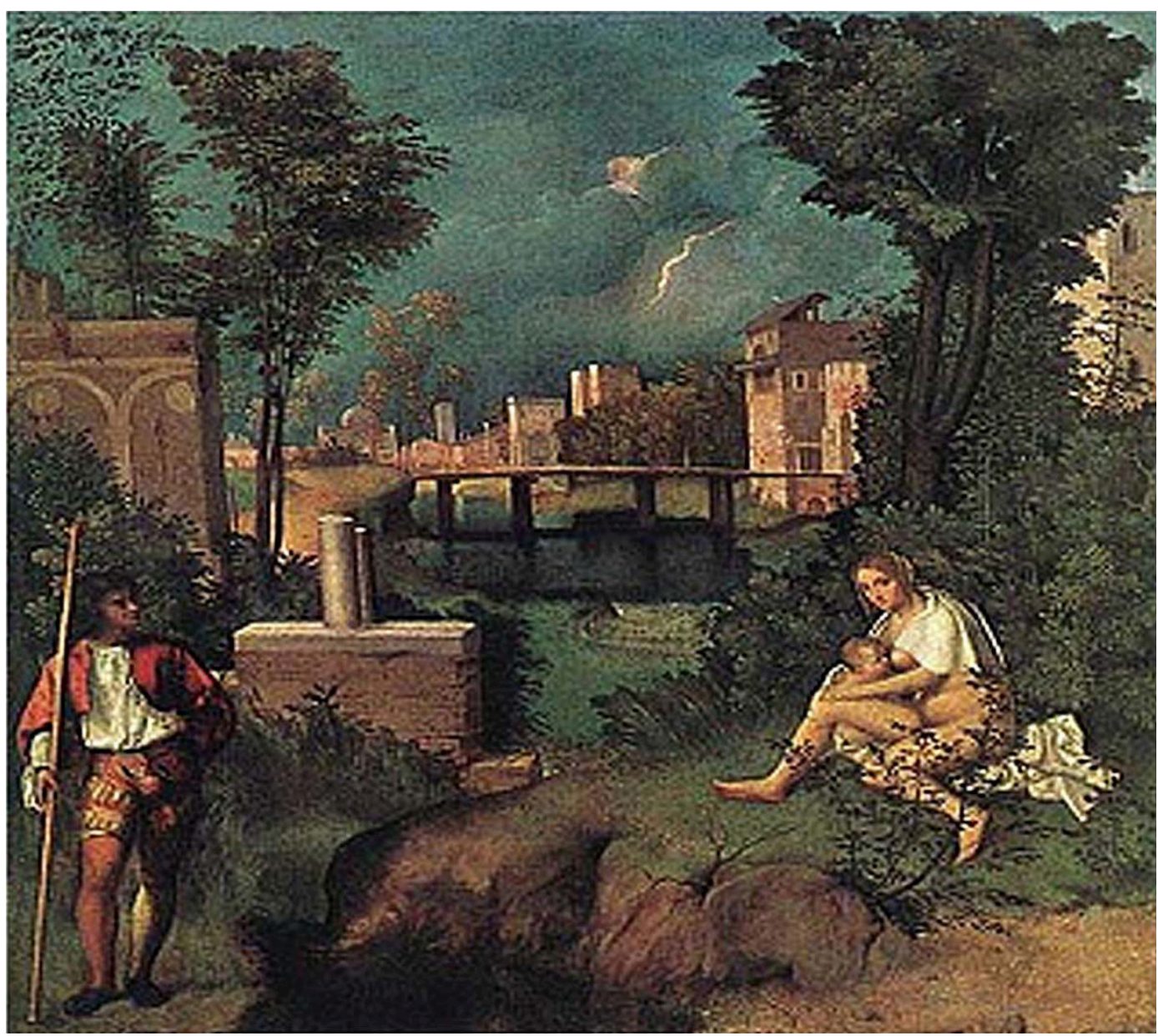

FIGURA 1. Veneziano Giorgine, A Tempestade, 1505.

Fonte: http://www.britanica.com

A ciência moderna que está sendo prenunciada na filosofia, na obra de Bacon, é, sobretudo, expressa na Arte, a partir de uma linguagem estritamente diversa. Conforme Abrão (1999, p.143-146), através da Arte inaugura-se uma nova forma de definir o espaço, a perspectiva passa a compor as obras e expressa uma maneira definitivamente distinta de ver o mundo. Também aqui a matemática assume papel central, na medida em que a retratação do mundo requer a métri- ca perfeita, que apenas esta proporciona. Pode-se dizer que "a perspectiva inventa uma nova imagem do espaço". (ABRÃO, 1999, p.146). Uma obra-prima da pintura renascentista que não analisaremos aqui, mas que simboliza a nova imagem do espaço é A Escola de Atenas de Rafael (1510-1511). De acordo com Janson (1988), nesta obra, corpo e espírito, ação e sentimento, encontram-se equilibrados, simetria e interdependência revelam o despertar de um novo espírito humano. 


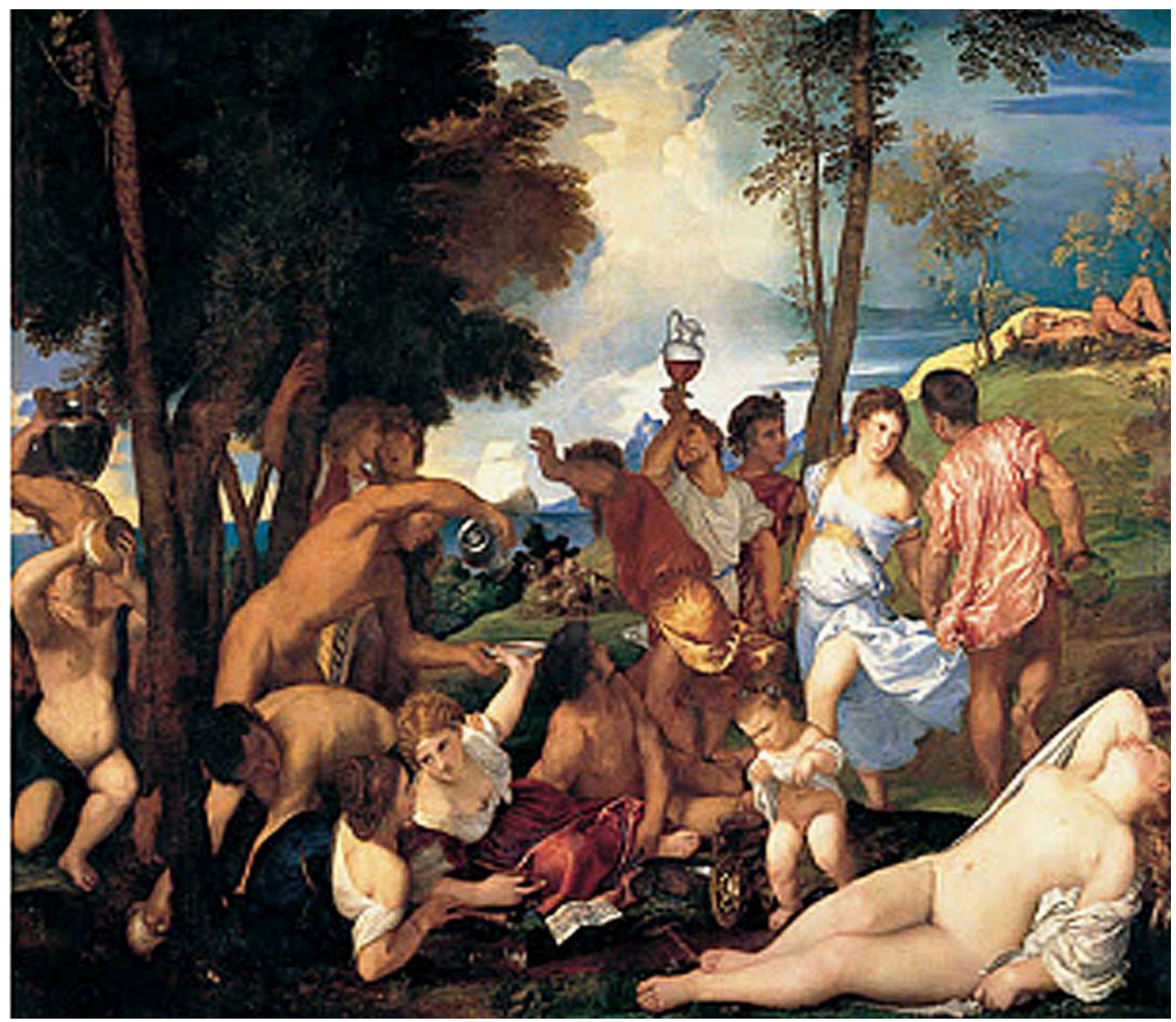

FIGURA 2. Ticiano, Bacanal, 1518.

Fonte: Janson, 1988, p. 222

Ao longo dos dois séculos seguintes, XVII e XVIII, a teorização do conhecimento tornou-se um campo efervescente. Um marco essencial nesta etapa foi a proposição teórica de Descartes, traduzida na dúvida metódica. A investigação dos fenômenos naturais adquiriu mais elementos para a compreensão da realidade. De acordo com Descartes (ABRÃO, 1999) a compreensão requer a redução da diversidade das coisas, até chegar à mínima parte comum. A partir daí, é preciso dividir as partes de que se compõe o todo até chegar ao elemento mais simples, o que constitui o procedimento de análise. Em seguida, deve-se realizar a operação inversa, a síntese, que permite a recomposição do simples ao complexo, considerado o procedimento capaz de instrumentalizar a compreensão da realidade. Neste caminho, não se deve omitir nada, sob pena de comprometer a conclusão. Através de Descartes tomava corpo a base científica e metodológica de investigação, que seria responsabilizada pela especialização que a ciência moderna viria a assumir.

Conforme a teoria do conhecimento proposta por Descartes, a representação constitui a operação que converte as coisas em objetos a partir da certeza absoluta na capacidade humana de pensar, que explica por sua vez a própria existência ("Penso, logo existo”). De forma cada vez mais palpável, percebemos através da filosofia como o humano justificadamente foi se tornando senhor da natureza. Contudo seria ao longo do século XIX, que a dominação da natureza atingiria o auge e seria consolidada, com o advento da Revolução Industrial. 
Claval (2004) demonstra, que no interstício em que ocorreu o nascimento e consolidação das bases filosóficas da ciência moderna, a Geografia persistiu presa às suas raízes disciplinares definidas na Antiguidade. A partir do colonialismo, do século XVI ao XVIII, a relevância desta função não apenas se renovou como foi reforçada. O geógrafo associava levantamentos astronômicos às pesquisas de arquivo, tendo em vista definir distâncias e longitudes. Os avanços tecnológicos que marcaram o século das Luzes (o século XVIII) tornaram viável a leitura das longitudes, permitindo que parte desta responsabilidade saísse do campo profissional geográfico e assumisse caráter disciplinar, independente da Geografia. É o que ocorre com a cartografia, que teria se tornado um campo da engenharia (CLAVAL, 2004, p.13).

É também no XVIII, que a concepção de natureza passou a se inspirar na Física, a natureza "máquina". Expressava-se assim o fruto do triunfo da física e da matemática enquanto conjunto de proposições necessárias para a compreensão dos fenômenos naturais. A transição para o capitalismo teve neste momento um ponto alto, na medida em que a produção fabril permitiu à burguesia consolidar o domínio do processo técnico da manufatura. Desta forma, superava o modo de produção artesanal que havia sido predominante no feudalismo. Estavam dadas as condições para o fenomenal desenvolvimento das forças produtivas através da divisão processual do trabalho, o que possibilitou o surgimento da indústria. Vale sempre lembrar que esta dinâmica de transição para o capitalismo foi absolutamente desigual no seu ritmo de expansão em termos espaciais, e extremamente concentrada em algumas regiões da Europa ocidental, com o pioneirismo da Inglaterra.

É possível pensar na indústria como uma espécie de corolário do processo de dominação da natureza pelo homem. Nas palavras de Santos (1992), a história do homem foi uma história de ruptura com seu entorno, que o capitalismo a partir de sua base centrada no indivíduo acelerou de forma brutal. Ainda para Santos (1986, p.172):

A natureza se transforma pela produção e não há produção sem instrumentos de trabalho. Desde o início dos tempos históricos, o homem produtor idealizava e construía os seus instrumentos de trabalho com suas próprias mãos; transportava-o como um prolongamento imediato do seu corpo; havia uma comunhão quase total entre o homem e os instrumentos que ele utilizava e manipulava na tarefa cotidiana de produzir. Era assim que ele imprimia a sua marca sobre a natureza: transformando-a.

Os acontecimentos do século XIX certamente passaram a requerer outro olhar científico sobre $o$ mundo, o que se estendeu para todos os campos da ação e do pensamento humano. Paulatinamente, a idéia predominante de natureza máquina do século XVIII foi sendo substituída pela imagem do sistema orgânico. Neste sentido, houve um movimento de reação ao racionalismo, corrente que tinha na razão a primazia de todo conhecimento. Este seria corroborado por vários pensadores, dentre eles, Kant, Schelling e Hegel (GOMES, 2005). Contudo, ao longo do tempo, especialmente em função do empirismo, cujas raízes remontam a Francis Bacon, haverá a total negação de qualquer elemento que implicasse a subjetividade.

A sociedade capitalista representa $\mathrm{per}$ si o processo fundador de um cenário calcado e que se desenvolve a partir das contradições, observáveis nas reflexões advindas das correntes dominantes, bem como das contracorrentes do pensamento filosófico. A Geografia, por sua vez, desde a Antiguidade se apresentava como a descrição e criação da imagem do mundo. Como indica Gomes (2005, p.28) "a história da ciência geográfica pode, então, ser considerada como a história do imago mundi da própria modernidade". Inicialmente, isto se deu através fundamentalmente da cartografia. Mas, na medida em que se desenvolveu o fundamento científico que viabilizou a especialização como elemento de precisão do conhecimento, foi desencadeada esta mesma necessidade (de recorte de objeto) no discurso geográfico. Desta forma, possibilitaria conectá-la à nova ordem científica que se instaurava. 
No movimento de reação ao racionalismo emergiram várias correntes de pensamento, para as quais a razão humana não se revelava suficiente para a compreensão dos fenômenos. Conforme Gomes (2005, p.33),

... a prática experimental da ciência racionalista é falsa, pois o julgamento se faz a partir de uma exterioridade que não corresponde à essência do fato observado. Em lugar de explicar a partir da construção de um sistema abstrato e racional, a ciência deveria compreender o sentido das coisas. Enquanto para o racionalismo, pelo método científico, deveriam ser criadas as condições de distanciamento dos fatos, para este outro ponto de vista, assim agindo, perdemos a possibilidade de verdadeiramente compreender a riqueza da diversidade dos fenômenos.

Retomada contemporaneamente no debate sobre a reunificação científica dos elementos da razão e emoção, a problemática que envolve o papel da ciência esteve presente sob formas diversas ao longo do século XIX. O racionalismo "arrancou", por assim dizer, o homem da natureza, o que concedeu justificati$\mathrm{va}$, bem como trouxe instrumental técnico e teórico para a dominação e transformação do entorno. A corrente romântica, em outro pólo, apoiou-se na definição da idéia de humanidade a partir de uma relação na qual o ser humano é pertencente à natureza. Neste sentido, a compreensão dos fenômenos passou a exigir um olhar que extrapolasse a racionalidade científica e requeria recursos de percepção e interpretação das interações do homem com seu meio, expressas sob a forma da cultura.

O mundo foi compreendido como composto de "aglomerados geoculturais" o que exerceu influência importante para valorização de sistemas nacionais, que por sua vez, aparecem também no gérmen da Geografia moderna. História e natureza foram os dois temas preferenciais do romantismo. Gomes (2005) cita tanto Werner, geólogo e mineralogista, como Goethe, escritor e cientista, que expressaram esta fusão entre a linguagem da razão e a organização da natureza. Em
Goethe (1821), a natureza se apresenta como animal vivo e composto de conexões harmônicas; sua concepção de Terra se aproxima neste sentido àquela que seria desenvolvida pelos geógrafos da escola francesa.

A pulsante relação homem-natureza do romantismo se expressa na linguagem artística através da obra de escritores e pintores. Goethe nos presenteia com a profusão do romantismo, em sua obra-prima da literatura romântica, Os sofrimentos do jovem Werther, ao tempo em que revela uma percepção distinta da relação homem-natureza a partir da Arte.

(...) Quando em torno de mim os vapores elevam do meu vale querido, e o sol a pino procura devassar a impenetrável penumbra da minha floresta, mas apenas alguns dos seus raios conseguem insinuar-se no fundo deste santuário; quando, à beira da cascata, ocultas sob os arbustos, descubro rente ao chão mil diferentes espécies de plantazinhas; quando sinto mais perto do meu coração o formigar de um pequeno universo escondido embaixo das ervinhas, e são os insetos, moscardos de formas inumeráveis cuja variedade desafia o observador, e sinto a presença do Todo-poderoso que nos criou à sua imagem, o sopro do Todo-Amante que nos sustenta e faz flutuar num mundo de ternas delícias (GOETHE, 1821, p.3)

Ainda neste período, os paisagistas ingleses William Turner e John Constable "esclarecem com suas obras quais podem ser as atitudes do homem moderno frente à realidade natural", (ARGAN, 1992, p.38). Mesmo trilhando caminhos estéticos distintos Turner e Constable reafirmam a natureza como um ambiente de vida. A tela Chuva, vapor e velocidade (FIG. 3), pintada em pleno século da revolução industrial, expressa os reflexos da velocidade dos tempos modernos sobre o ambiente transformado. Refletiam-se elementos sensíveis e racionais, dispostos e capazes de subsidiar uma leitura complexa das relações homemnatureza. 


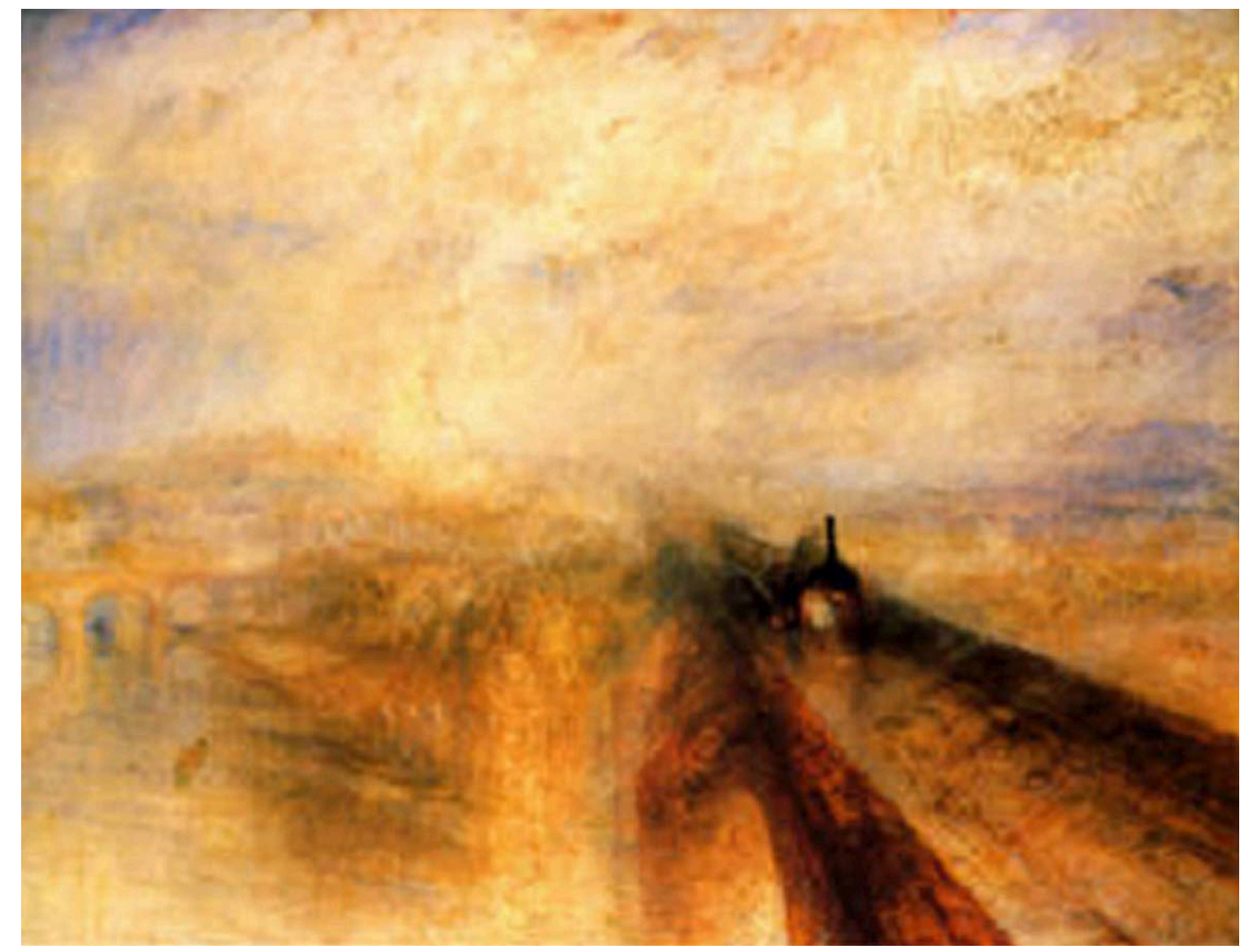

FIGURA 3. Willian Turner, Chuva, vapor e velocidade, 1844.

Fonte: National Gallery, London.

Ainda assim, até o início do século XIX a Geografia continuava presa à idéia de física do mundo, ligada às narrativas de viagens e incumbida de interpretar a dinâmica da natureza e suas relações com a marcha histórica (GOMES, 2005).

O marco de renovação no pensamento geográfico se apresentou a partir da obra de Alexander Von Humboldt (1769-1859). Nascia uma nova vertente do estudo, dirigida para um esforço de síntese entre a linguagem científica moderna e a percepção artística. Em sua obra, revela-se o esforço sistemático de reunir às tradicionais narrativas de viagens a preocupação com a análise comparativa e o estabelecimento dos raciocínios gerais e evolutivos. Conforme Gomes (2005), estão explicitamente contidos na obra de Humboldt a preocupação do naturalista francês, Georges-Louis Leclerc, conde de Buffon, quanto a uma natureza vista como conjunto orgânico; assim como a idéia de cadeia explicativa de Diderot; e, por fim, a causalidade histórica de Voltaire.

Na medida em que seu discurso incorporava o tom racional e lógico, ao mesmo tempo em que buscava apoio na linguagem poética e emocional, Humboldt transformou-se em expressão do romantismo alemão no campo científico. Seus laços com a corrente romântica eram estreitos a ponto de se explicitarem nas influências pessoais, especialmente a de Goethe, na elaboração de seu trabalho.

A partir das orientações de Humboldt, a Geografia passaria a englobar reflexões sobre o homem e sobre a natureza. Entre 1799 até 1804, a expedição de Humboldt ao Novo Mundo percorreu a região que intitulou de equinocial, hoje correspondente à Venezuela, Cuba, Colômbia, Equador, Peru e México. Sua viagem foi marcada pelo novo espírito científico 
de investigação. A realização do mapeamento e análise detalhada das paisagens encontradas possibilitou um legado de conhecimento sobre diversos aspectos, em especial dos elementos geográficos, tanto na perspectiva física, quanto cultural (KOHLHEPP, 2006).

As contribuições sensíveis do campo da Arte exerceram um forte legado sob a ótica científica de Humboldt, bem como de todos aqueles que incorporaram os princípios do romantismo. Os instrumentos científicos, métricos e quantitativos, foram associados ao recurso permanente da pintura. A síntese da paisagem apenas se completava na medida em que eram associados os aspectos estéticos e da percepção. Conforme o próprio Humboldt (Apud Alves 2005, p.69) “(...) a ciência é o espírito aplicado à natureza, mas o mundo exterior só passa a existir para nós no momento em que, pela via da intuição se reflete no nosso interior."

\section{DE HUMBOLDT A VON MARTIUS NA GEO- GRAFIA DO NOVO MUNDO}

A partir da expansão colonialista do século XVI surgiu um "novo" mundo, responsável pela provocação de outros olhares e, neste sentido, novas demandas ao pensamento geográfico. Ainda assim, a empresa colonial da América por muito se manteve fechada às descobertas e às reflexões das ciências em geral, inclusive das ciências naturais. A ação de rapinagem das Coroas colonialistas foi predominantemente insensível ao conhecimento efetivo da realidade encontrada nos trópicos.

Tratando da história da devastação da floresta Atlântica, Dean (1996) desmistifica a relação do homem com a floresta, ambiente desde sempre inóspito para o humano. Este antagonismo acompanha as sociedades humanas, o que torna evidente que os colonizadores não encontraram intacta o ambiente natural deste continente americano. Imbuídos do interesse mercantil de exploração e inebriados pela crença na abundância de espécies naturais, apenas muito tardiamente este espaço tornar-se-ia palco de interesse e de disponibilidade de estudos e pesquisas. A ignorância e o desperdício caminharam lado a lado nesta empreita- da de dominação territorial conhecida como colonização do "novo" mundo.

Foi, no entanto, na etapa de consolidação da ciência moderna, entre os séculos XVIII e XIX, que os cientistas tornaram-se imbuídos de uma nova visão acerca do valor das expedições científicas. Exatamente neste contexto, Humboldt obteve habilidosamente a concessão da Coroa espanhola para o estudo minucioso de vastas regiões da América Central e do Sul. Sua entrada no território de domínio português, no entanto, foi vetada.

Apenas a partir de 1808, com a transferência da família real portuguesa para o Brasil, foragida das tropas de Napoleão, iniciaram-se as primeiras expedições científicas à América portuguesa, graças à abertura dos portos às nações estrangeiras. Entre os viajantes que aqui estiveram nesta época, destacam-se os naturalistas Spix e Martius, Eschwege, Saint-Hilaire, o príncipe Maximiliano von Wied-Neuwied, o barão Langsdorff, cônsul da Rússia, os pintores Debret, Rugendas, Ender e os ingleses John Luccock, Maria Graham e John Mawe. (DEAN, 1996).

Em função das próprias condições de transferência da Corte portuguesa, que evidenciavam a decadência econômica e política do país, o reconhecimento e a exploração do potencial produtivo brasileiro ascendiam como elementos imperativos. Aos olhos da Coroa, o patrimônio natural seria salvaguarda da riqueza do império colonial. Segundo Dean (1996, p.140):

\section{(...) a Coroa não hesitou em instalar em sua nova corte poderosos instrumentos de inves- tigação do mundo natural: uma gráfica, uma biblioteca, uma escola de medicina, um la- boratório de análises químicas, uma cátedra de ensino agrícola (em Salvador) e uma aca- demia militar, cujas funções incluíam enge- nharia civil e mineração.}

Neste período, duas instituições criadas constituiriam o berço da rede das ciências naturais brasileira, o Jardim Botânico do Rio de Janeiro e o Museu de História Natural. Este último, embora tenha sido cria- 
do em 1808 chegou a ser fechado em 1813 para ser reaberto apenas a partir da influência da arquiduquesa austríaca Maria Leopoldina. Ao vir para o Brasil, Leopoldina abriu o Brasil para outras nações do ponto de vista científico; sua ligação com as ciências naturais possibilitou que viesse para o Brasil acompanhada por um grupo prestigioso de investigadores da natureza, cientistas austríacos e germânicos. (DEAN, 1995, p. 140) Dentre estes estavam Johann Emanuel Pohl, Karl Friedrich Philipp von Martius e Johan Baptista von Spix (FERREIRA, 2006).

A botânica estava entre os campos de estudos científicos mais apreciados do período. No entanto, não havia delimitação precisa entre as áreas de pesquisa, especialmente em função da formação dos pesquisadores, quase todos de origem germânica ou francesa. Em seus países de origem fervilhavam as novas idéias e muitos destes cientistas eram influenciados pela corrente romântica, que já havia trazido contribuições importantes para os estudos do continente americano através do extenso e profundo trabalho de Humboldt e do botânico Aimé Bonplant.

Muitas destas expedições foram compostas por cientistas e artistas, sendo que alguns desses se tornaram independentes no objetivo de retratação da realidade vivenciada. A profusão de cores, o calor, a diversidade étnica, enfim tudo questionava a métrica, a forma neoclássica da pintura do século XIX. Este desafio também se apresenta como referência para a compreensão dos contornos assumidos por este "novo" mundo.

Embora um artista possa retratar com precisão esta ou aquela flor no solo da floresta, a floresta inteira desafia a habilidade artistica. Nenhuma pintura ou foto - que não passam de meras obras - consegue captar a presença envolvente, misteriosa, da floresta, sua "solidez plástica". (DEAN, 1996, p.142)

A história da Geografia brasileira teria uma importante propulsão a partir do século XIX, no entanto, suas raízes remontam à primeira etapa da colonização. Elementos de caracterização da vegetação estão presentes já na carta de Pero Vaz de Caminha.
Os padres Manuel da Nóbrega (1559) e José de Anchieta produziram relatos que traduziam observações sobre a cultura do fumo e sobre a vegetação em geral. Nicolas Durand de Villegaignon e André Thevet descreveram uma diversidade considerável de aves. Estas descrições eram marcadas pela composição entre a observação e a incorporação dos elementos fantasiosos, típicos da produção do século XVI (CAMARGO, 2002).

Segundo Camargo (2002), ainda no século XVI foram registrados escritos mais objetivos sobre o ambiente geográfico do Brasil, dentre eles o de Jean de Lery (1578) e Fernão Cardim (1625), tendo este último publicado "Do clima e da terra do Brasil". Mas, chama a atenção o tratado enciclopédico realizado pelo fazendeiro Gabriel Soares de Souza, do qual resultou sua sugestão ao então Rei Felipe I, acerca da relevância do saber geopolítico, isto é, da compatibilização entre a política administrativa da colônia e suas condições geográficas.

Durante o governo de Maurício de Nassau no período de domínio holandês no nordeste brasileiro, o trabalho científico e o artístico, que se vinculava ao primeiro, foram estimulados. Destaca-se nesta etapa a vinda de Jorge Marcgrave (1610-1644), responsável por fundar um observatório astronômico em Recife, então capital da colônia. As pesquisas de Marcgrave assumiram intenso caráter geográfico e cartográfico, seguindo seu objetivo de inventariar o domínio natural do território. Para Camargo (2002), a descrição etnográfica seguia objetivo claro, no sentido de elucidar o entrosamento e a obediência ao fator geográfico nas práticas e na distribuição da população.

Já no final do século XVIII, Martinho de Melo e Castro responsável por substituir o Marquês de Pombal também enviou expedição científica ao Brasil com o intuito de estudar as riquezas naturais, clima e núcleos de povoamento. Dirigida por um brasileiro, Alexandre Rodrigues de Almeida, naturalista baiano, esta expedição gerou um acervo bastante rico, que instalado em Lisboa terminou sendo capturado pelos franceses após a invasão de Portugal pelas tropas napoleônicas (CAMARGO, 2002). 
É compreensível, no entanto, que de forma mais contínua e consistente, os estudos científicos realizados no Brasil a partir da transferência da Corte tenham se tornado mais expressivos. Nesta etapa, interessa destacar a obra dos naturalistas que estiveram em solo brasileiro e desenvolveram seus trabalhos a partir da concepção romântica, que havia marcado o trabalho de Humboldt na América. Podemos dizer que aqueles que mais se aproximaram ou mais veementemente reivindicaram a herança humboldtiana foram Friederich Von Martius e Auguste Saint Hilaire.

Conforme Kury (2001) deve-se salientar que a atuação dos viajantes naturalistas era a expressão de uma vertente científica que defendia a necessária fusão entre a pesquisa metódica associada à percepção, à tradução sensível da realidade. Segundo esta autora, o debate entre Georges Cuvier e Humboldt retrata de forma estupenda um embate que ressonaria a partir daí, favoravelmente à posição do primeiro e em detrimento do caminho propugnado pelos cientistas românticos. Para Cuvier, a ausência da experiência sensorial da pesquisa científica realizada no ambiente controlado (gabinetes, jardins botânicos e outros) era compensada por todas as possibilidades de acesso às informações comparadas, às bibliotecas, sendo, portanto, superior àquilo que se podia produzir a partir da experiência proporcionada pelas viagens. Segundo Cuvier " $O$ viajante percorre apenas um caminho estreito. É unicamente no gabinete que se pode percorrer o universo em todos os sentidos" (Apud KURY, 2001, p.864).

Por outro lado, para os viajantes que deram continuidade à linha de trabalho de Humboldt, a experiência estética compunha a atividade científica. O gosto e a sensibilidade integravam o processo de construção do conhecimento, o que não significava prescindir da medição de maneira sistemática e precisa no que se refere aos fatores físicos. O romantismo alemão, a partir de Kant, depositava na arte a capacidade de levar o cientista ao alcance daquilo que a razão, por meio da filosofia, não tornaria possível. Neste sentido, o artista proporcionaria o que os filósofos não seriam capazes de proporcionar em termos de apreensão da realidade.

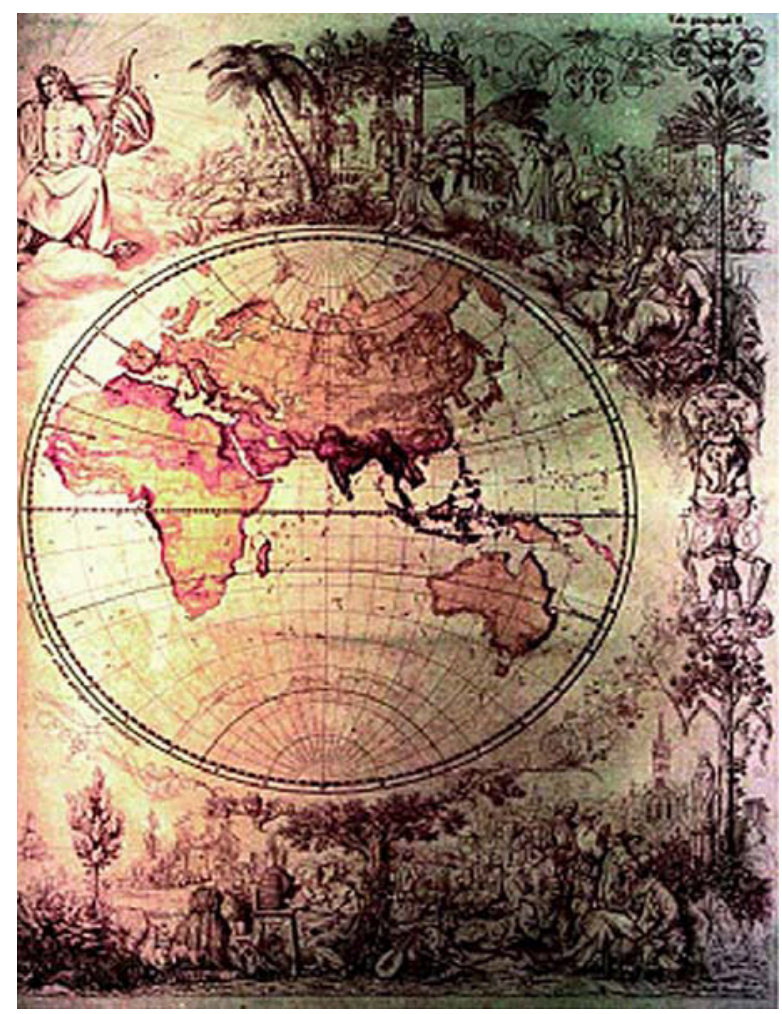

FIGURA 4. Carl Friedrichi P. Von Martius.

Fonte: Kury, 2001. 
A expedição liderada por Martius permitiu classificações precisas, organização de herbários e trabalhos em antropologia e história. Mas este trabalho foi organizado e descrito a partir do exercício da sensibilidade. Registra-se a busca incessante dos pesquisadores por traduzir aquilo que transcende aos elementos tangíveis da realidade. A FIG. 4 é um exemplar desta proposição do pesquisador em busca de uma síntese, que traduzisse os elementos expressivos do imaginário, da abundância e diversidade florestal, da imposição religiosa, conectadas à concreta demarcação do posicionamento geográfico.

Em sua obra, derivada dos estudos realizados na expedição pelo Brasil, Flora Brasiliensis (de 1840), Martius procurou articular texto e imagem de forma orgânica (KURY, 2001). A natureza é tratada nesta obra como um conjunto de indivíduos, animais e vegetais. "Para os naturalistas do século XIX, a ciência devia buscar descrever a totalidade de elementos que atuavam em um fenômeno local. É como se cada parte contivesse o todo." (KURY, 2001, p.870)

Vale destacar que as obras artísticas ao serem incorporadas no corpo de trabalho das expedições passaram a cumprir uma função, qual seja a de viabilizar a expressão do fenômeno sob outra matriz que não apenas a predominante, a escrita. Isto vale tanto para a expressão pictórica, como para a poética. A referência poética esteve freqüentemente em Goethe, mas também em outros literatos. Isto também vale para a pintura, muitas delas pouco importantes do ponto de vista da produção artística em si. Algumas expedições, por sua vez, contaram com pintores especialmente contratados para a função de traduzir os fenômenos e a realidade sócio-cultural dos locais visitados, como foi o caso do pintor Rugendas, assim como Taunay, que participaram da expedição organizada pelo barão Georg Heinrich Von Langsdorff.

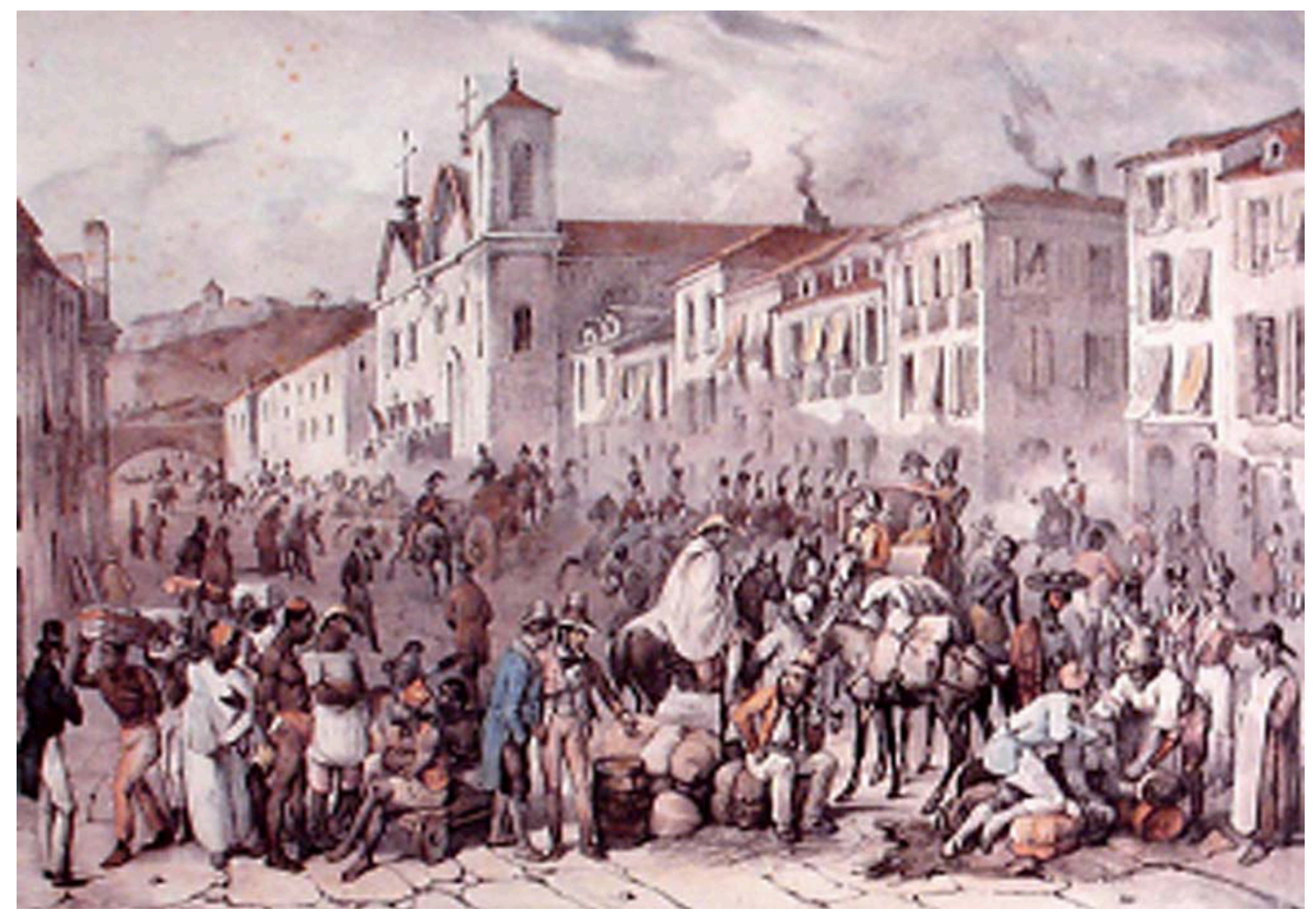

FIGURA 5: Johan M. Rugendas. Rua Direita.

Fonte: Museu Castro Maya/Iphan, Rio de Janeiro. 
Ambos, cientista e artista viam-se confrontados com uma realidade tanto diversa, como complexa, a ser desvendada, compreendida e, do ponto de vista do interesse colonial, rastreada. $\mathrm{O}$ "novo" mundo foi perdendo paulatinamente o caráter de "outro" mundo, tornando-se desencantado, da visão paradisíaca e da descrição idílica do bom selvagem à condição de mundo concreto, de natureza a ser dominada pelo conhecimento. Ilustrando esta condição, Siqueira (2006) trata a obra de Rugendas, para quem a cidade do Rio de Janeiro era tão difícil de representar, quanto a paisagem tropical. Em sua tela Rua Direita, Rugendas (FIG. 5) expressa exatamente este desafio do inesperado, da ausência da uniformidade que requer do artista um novo olhar.

É possível dizer que o esforço de síntese realizado pelos cientistas românticos se aproxima da abordagem ecológica contemporânea, na medida em que explora a relação homem-natureza a partir da ótica das correlações e cooperações. De forma impressionante, a empresa destes cientistas, tanto Humboldt, como Martius e outros que seguiram a mesma proposição, buscou fundir no estudo da natureza todos os demais elementos relevantes à compreensão do mundo e de seus fenômenos.

Os estudos de Humboldt proporcionaram elementos essenciais para a compreensão dos fenômenos relativos ao clima e vegetação e, neste sentido, constituíram elementos fundantes da moderna Geografia física. Por outro lado, trouxeram as análises de cunho regional como contribuição para o campo da Geografia Humana, que também viria a se consolidar moderna-mente. Tal como Martius, aqueles cientistas, que seguiram esta mesma proposição, deram continuidade a uma linha de construção do conhecimento que buscava a compreensão do mundo a partir da unificação entre elementos da razão e da sensibilidade. Partia-se de um pressuposto muito claro de que apenas seria possível apreender a realidade partindo de sua complexidade. Para Morin (2000b, p.1), "o problema do conhecimento é um desafio porque só podemos conhecer, como dizia Pascal, as partes se conhecermos o todo em que se situam, e só podemos conhecer o todo se conhecermos as partes que o compõem".

\section{GEOGRAFIA: UMA CIÊNCIA EM BUSCA DA SÍNTESE E DA COMPLEXIDADE}

O conceito de paisagem a partir de Humboldt consolidou-se como elemento fundante da síntese entre os dois aspectos essenciais à ciência, o humano e o natural. Este conceito foi incorporado à Geografia e tornou-se vital até o início do século XX. Ao longo do tempo, é notório que o termo acabaria sofrendo modificações relevantes. (SALGUEIRO, 2001). Os reflexos da especialização científica, sob a égide do positivismo e da corrente neopositivista no século XX, seriam evidenciados também na ciência geográfica. Marcadamente nesta ciência, tornaram-se hegemônicos dois campos de produção do conhecimento, a Geografia Física e a Humana.

A Geografia, tal como nos propusemos a pensar nesta discussão, apresenta-se como uma ciência, que na sua fundação partiu da síntese e não da especialização. Nela apresentaram-se interconectados os campos dicotomizados pela ciência moderna, o natural e o social, bem como o racional e o sensível. Deve-se considerar que a roupagem moderna, racionalizadora e matematizada, encontrou um campo extremamente fértil nas ciências naturais e marginalizou em grande parte a ciência social, cujo objeto, em geral, é intrinsecamente subjetivo, tendo realizado o mesmo com o campo da Arte. Este embate foi internalizado por esta ciência, o que se refletiu especialmente no campo epistêmico.

Contemporaneamente, várias questões que pertenceram ao seu marco fundador voltaram a ser colocadas em meio ao debate reaberto no último quartel do século XX, que gira em torno da crise da ciência moderna. Sem dúvida, são controversas a extensão e a profundidade desta crise, mas suficientemente potentes e capazes de suscitar a criatividade e a renovação do pensamento científico. Refletindo sobre a " $c e$ gueira do conhecimento", Morin (2000a) demonstra que o conhecimento comporta tanto o erro, como a ilusão. Em busca da eliminação de ambos, erro e ilusão, a razão foi alçada ao primeiro plano da ciência. No entanto, a racionalidade teria se transformado em racionalização, entendida como sistema lógico, perfei- 
to e irrefutável. Neste sentido, todos os elementos da percepção, da afetividade, portanto da subjetividade humana, teriam sido descartados. Perverteu-se assim a busca do conhecimento em arrogância, distanciada da compreensão efetiva da sociedade humana.

Através da especialização, a natureza converteu-se em um campo do conhecimento científico da Geografia, pertencente a uma de suas especialidades de forma mais explícita, a Geografia Física. Foi a fragmentação científica que se responsabilizou pela existência deste campo, com objeto aparentemente tão distante do campo da Geografia Humana. Conforme Suertegaray (2001), muitos teóricos da Geografia física buscaram reencontrar a análise integrada do meio físico a partir de conceitos como paisagem, posteriormente, geosistema e sistemas físicos. De acordo com esta autora, este caminho foi retomado a partir dos anos 70 , quando veio à tona a discussão ambiental e com ela o resgate da ecologia e da idéia de relação entre os organismos e seus ambientes.

Conforme Mathews (2004), a modernidade trouxe à Geografia a percepção da necessária separação entre o mundo humano e biofísico. Porém, a questão ambiental teria recolocado a necessária inter-relação entre os dois campos, o que tem se apresentado de forma mais contundente na produção teórica dos geógrafos físicos. As novas tendências de pesquisa, em especial aquelas que estão focadas no meio ambiente, estariam provocando uma retomada do pensamento sintético na Geografia. Beaumont (2004) critica a insuficiência de estudos profundos na perspectiva ambiental a partir da Geografia, mas destaca que entre os geógrafos que estão dedicados a esta temática existe uma profusão de questões relacionadas à história e antropologia, que confirmam a tendência da síntese.

Dentro deste contexto, quando se coloca a "necessidade de um pensamento complexo" (Morin, $2000 b)$ e que se percebe um novo percurso da Geografia em busca da síntese científica é que também se reforça, a nosso ver, a importância de refletir sobre as contribuições dos naturalistas viajantes. Baseados na matriz filosófica do romantismo, em sua vertente alemã, consolidaram em suas obras no século XIX uma preocupação e uma experiência de síntese, que de antemão deve ser valorizada como referência histórica.

Neste primeiro decênio do século XXI, mediante a esquizofrenia do sistema capitalista e suas crises crônicas, as verdades científicas permanecem sendo questionadas, torna-se possível superar a matriz de pensamento que considerou o humano como centro do mundo, mestre e dominador da natureza. É possível que esta nova tendência à complexidade também seja abortada como o foi no século XIX, no entanto, no tempo presente podemos nos dispor às proposições ousadas como fizeram Humboldt e todos os pensadores que por ele foram influenciados.

\section{REFERÊNCIAS}

ABRÃO, B. S. História da Filosofia. São Paulo: Nova Cultural, 1999.

ALVES, V. E. L. A obra de Humboldt e sua provável influência sobre a antropologia de Franz Boas. Revista Espaço e Tempo, GEOUSP, São Paulo, n. 18, p. 67 79, 2005.

ARGAN, Giulio Carlo. Arte Moderna. Tradução Denise Bottman. São Paulo: Companhia das Letras,1992.

BARBARELE, Giorgine. A Tempestade. (1505). Óleo sobre tela, $0,82 \mathrm{~m} \times 0,73 \mathrm{~m}$. Academia de Veneza. Disponível em: $<$ http://www.britannica.com/EB checked/topic/586736/The-Tempest $>$. Acesso em jun. 2008.

BEAUMONT, P.,PHILO, C. Environementalismo and Geography - The Great Debate? In: MATHEWS, J.A., HERBERT, D. Unifying Geography - Common heritage, shared future. London. New York. Oxfordshire: Routledge, 2004.

BACON, F. Novum Organum ou Verdadeiras indicações acerca da interpretação da natureza. São Paulo: Nova Cultural, 1999.

CAMARGO, J. C. G. A contribuição dos cronistas coloniais e missionários para o conhecimento do territó- 
rio brasileiro. Revista de Geografia da UFC, ano 1, n. 2, 2002.

CLAVAL, P. A Revolução pós-funcionalista e as concepções atuais da Geografia. In: MENDONÇA, F. \& KOZEL, S. (Org.). Elementos da Epistemologia da Geografia Conteporânea. Curitiba: Ed. da UFPR, 2002.

DEAN, W. A ferro e fogo: a história e a devastação da Mata Atlântica brasileira. Trad. Cid Knipel Morei-ra. São Paulo: Companhia das Letras, 1996.

FERREIRA, R. S. Henry Water Bates: um viajante naturalista na Amazônia e o processo de transferência da informação. Revista Ciência da Informação, Brasília, v. 33, n. 2, p. $67-75,2004$. Disponível em: $<\underline{\text { http: } /}$ /www.ibict.br/cionline/viewarticle.php?id $=129 \&$ layout $=\mathrm{html}>$ Acesso em abr. 2008.

GOMES, P. C. C. Geografia e modernidade. Rio de Janeiro: Bertrand Brasil, 2005.

GOETHE, W. Os sofrimentos do jovem Werther. Porto Alegre: L\&PM, 2003.

JANSON, H. W. Iniciação à História da Arte. Trad. Jeffeerson Luis Camargo. São Paulo: Martins Fontes, 1998.

KOHLHEPP, G. Descobertas científicas da Expedição de Alexander von Humboldt na América Espanhola (1799 - 1804) sob ponto de vista geográfico. Revista de Biologia e Ciências da Terra. v. 6, n. 1, p. 260 $-278,2^{\circ}$ sem. 2006.

KURY, L. Viajantes-naturalistas no Brasil oitocentista: experiência, relato e imagem. Revista História-Ciência, Saúde. Manguinhos, v. VIII (suplemento), 2001.

MATHEWS, J. A., HERBERT, D. (Org.). Unifying Geography - Common heritage, shared future. London. New York. Oxfordshire: Routledge. 2004

MORIN, E. "As cegueiras do conhecimento: o erro e a ilusão". In: Os Sete saberes necessários à educação do futuro. São Paulo: Cortez, Brasília, DF: UNESCO, 2000.

. "Da Necessidade de um pensamento complexo.” In: MARTINS, F. M. \& SILVA, J. M. (Orgs.). Para Navegar no século XXI-Tecnologias do Imaginário e Cibercultura. Porto Alegre: EDIPUCRS, $2000 \mathrm{~b}$.

RUGENDAS, J. Rua Direita. 1827-1835. Rio de Janeiro. Museu Castro Maya/Iphan.

SALGUEIRO, T. Paisagem e Geografia. Finisterra, n. XXXVI, 72, p. $37-53,2001$.

SANTOS, M. A redescoberta da natureza. Aula inaugural da Faculdade de Filosofia, Letras e Ciências Humanas da USP. Revista Estudos Avançados. São Paulo, v. 6, n. 14, p. 95 - 106, 1992. Disponível em: $<$ http://www.scielo.br/scielo.php?script=sci_arttext $\&$ pid $=$ S0103-40141992000100007>. Acesso em maio 2008.

. Por uma geografia nova: da crítica da geografia a uma geografia crítica. 3.ed. São Paulo: Hucitec, 1986.

SIQUEIRA, V. B. Redescobrir o Rio de Janeiro. 19\&20. A revista eletrônica de dezenove vinte. v. I, n. 3, nov. 2006. Disponível em $<$ http://www.dezenove vinte.net>. Acesso em jun. 2008.

SUERTEGARAY, D. M. A natureza da Geografia Física na Geografia. Terra Livre. São Paulo, n. 17, p. 11 $-24,2^{\circ}$ sem. 2001.

TURNER, Willian. Chuva, vapor e velocidade. 1844 . Oil on canvas 0,91 m x 1,21 m. Disponível em: $<\underline{\text { http:/ }}$ /www.nationalgallery.org.uk $>$. Acesso em jun. 2008. 